\section{6 OPEN ACCESS}

\title{
Strategic target temperature management in myocardial infarction-a feasibility trial
}

\author{
Christoph Testori, ${ }^{1}$ Fritz Sterz, ${ }^{1}$ Georg Delle-Karth, ${ }^{2}$ Reinhard Malzer, ${ }^{3}$ \\ Michael Holzer, ${ }^{1}$ Peter Stratil, ${ }^{1}$ Mathias Stöckl, ${ }^{1}$ Christoph Weiser, ${ }^{1}$ \\ Raphael van Tulder, ${ }^{1,3}$ Clemens Gangl, ${ }^{2}$ Dieter Sebald, ${ }^{3}$ Andreas Zajicek, ${ }^{3}$ \\ Angelika Buchinger, ${ }^{3}$ Irene Lang ${ }^{2}$
}

\begin{abstract}
1 Department of Emergency Medicine, Medical University of Vienna, Vienna, Austria ${ }^{2}$ Division of Cardiology, Department of Internal Medicine II, Medical University of Vienna, Vienna, Austria ${ }^{3}$ Municipal Ambulance Service of the City of Vienna, Vienna, Austria
\end{abstract}

Correspondence to Dr Fritz Sterz, Universitätsklinik für Notfallmedizin,

Medizinische Universität Wien, Allgemeines Krankenhaus der Stadt Wien, Währinger Gürtel 18-20/6D, Wien 1090, Austria; fritz.sterz@meduniwien.ac.at

Received 10 July 2013 Revised 22 August 2013 Accepted 26 August 2013 Published Online First 24 September 2013

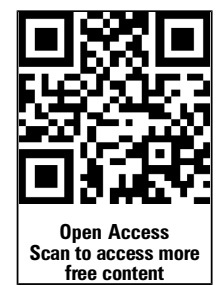

To cite: Testori C, Sterz F, Delle-Karth $\mathrm{G}$, et al. Heart 2013;99:1663-1667.

\section{ABSTRACT \\ Objective The purpose of this study was to} demonstrate the feasibility of a combined cooling strategy started out of hospital as an adjunctive to percutaneous coronary intervention $(\mathrm{PCI})$ in the treatment of STelevation acute coronary syndrome (STE-ACS).

Design Non-randomised, single-centre feasibility trial. Setting Department of emergency medicine of a tertiary-care facility, Medical University of Vienna, Vienna, Austria. In cooperation with the Municipal ambulance service of the city of Vienna.

Patients Consecutive patients with STE-ACS presenting to the emergency medical service within $6 \mathrm{~h}$ after symptom onset.

Interventions Cooling was initiated with surface cooling pads in the out-of-hospital setting, followed by the administration of 1000-2000 mL of cold saline at hospital arrival and completed by endovascular cooling in the catheterisation laboratory.

Main outcome measures Feasibility of lowering core temperature below $35.0^{\circ} \mathrm{C}$ prior to immediately performed revascularisation. Safety and tolerability of the cooling procedure.

Results In enrolled 19 patients (one woman, median age 51 years (IQR 45-59)), symptom onset to first medical contact (FMC) was $45 \mathrm{~min}$ (IQR 31-85). A core temperature below $35.0^{\circ} \mathrm{C}$ at reperfusion of the culprit lesion was achieved in 11 patients (78\%) within $100 \mathrm{~min}$ (IQR 90-111) after FMC without any cooling-related serious adverse event. Temperature could be lowered from baseline $36.4^{\circ} \mathrm{C}$ (IQR $36.2-36.5^{\circ} \mathrm{C}$ ) to $34.4^{\circ} \mathrm{C}$ (IQR $\left.34.1-35.0^{\circ} \mathrm{C}\right)$ at the time of reperfusion.

Conclusions With limitations an immediate out-ofhospital therapeutic hypothermia strategy was feasible and safe in patients with STE-ACS undergoing primary PCI.

Clinical trial registration http://www.clinicaltrials.gov/ ct2/show/NCT01864343; clinical trials unique identifier: NCT01864343

\section{INTRODUCTION}

Contemporary therapy in patients with ST-elevation acute coronary syndrome (STE-ACS) is to reperfuse the ischaemic myocardium as soon as possible to reduce infarct size and associated complications. ${ }^{1}$ However, reperfusion itself may provoke myocardial injury and increase infarct size. $^{2}$ There is currently no effective therapy available for preventing myocardial reperfusion injury. Infarct size is one of the main predictors of both short-term and long-term outcomes in patients with acute myocardial infarction. ${ }^{3}{ }^{4}$ Reduction or inhibition of myocardial ischaemia/reperfusion injury is therefore an important objective of current research to improve outcome after acute myocardial infarction.

Therapeutic hypothermia was effective in improving neurological outcome and reducing the risk of death in patients after cardiac arrest. ${ }^{5} 6$ In recent years, growing evidence in animal and human studies have documented or suggested the benefit of mild hypothermia for acute myocardial infarction $^{7-11}$ and cardiogenic shock. ${ }^{12}$ The value of therapeutic hypothermia in protecting myocardial tissue is still poorly explored and most likely multifactorial. ${ }^{13-15}$ The two major clinical trials investigating mild hypothermia via endovascular cooling catheters as an adjunct to acute myocardial infarction treatments failed to show a reduction in infarct size. ${ }^{16} 17$ Post hoc analysis of the data in these trials has shown that only a minority of patients were hypothermic at onset of reperfusion, and the subgroup of patients who were cooled to a temperature below $35^{\circ} \mathrm{C}$ prior to reperfusion did have a significant reduction in infarct size. A recent study by Götberg et $a l^{18}$ was able to show a significant reduction in infarct size in relation to myocardium at risk by the induction of prereperfusion hypothermia.

The aim of the present study was to investigate the feasibility and safety of a temperature care bundle, started in the out-of-hospital setting, combining surface, intravenous and endovascular cooling for induction and maintenance of prereperfusion mild hypothermia in awake patients with STE-ACS.

\section{METHODS}

The study was conducted according to the principles of the Declaration of Helsinki (V.4, 2004) and was approved by the ethical review board of the Medical University of Vienna (Protocol number: 492/2011; clinicaltrials.gov registration number: NCT01864343). Subjects were informed orally about the aims of the study and had to provide written consent for participation.

\section{Study endpoints}

Primary endpoint was to investigate the feasibility of a strategic cooling approach for achievement of 
prereperfusion hypothermia $\left(<35.0^{\circ} \mathrm{C}\right)$. Secondary endpoints were safety of the cooling procedure and adverse events within a follow-up period of $45 \pm 15$ days.

\section{Study population}

This was a prospective interventional study in a cohort of patients with acute STE-ACS. We included patients with at least 30 min of continuous typical chest pain, with ST-elevations of at least $0.2 \mathrm{mV}$ in two or more anatomically contiguous leads, presenting to the emergency medical service within $6 \mathrm{~h}$ after symptom onset. The possibility of an immediate transfer to the catheterisation laboratory for primary percutaneous coronary intervention was mandatory for inclusion. Patients were excluded if they were presenting with cardiac arrest, had a tympanic temperature below $35^{\circ} \mathrm{C}$ at presentation, had a history of chronic heart failure (defined as New York Heat Association classification II-IV) or presented in a condition of acute heart failure (defined by Killip classes II-IV). Furthermore, patients treated with thrombolytic agents, clinical signs of infection, endstage kidney disease or hepatic failure, recent stroke, haematological dyscrasias, oral anticoagulant treatment or severe pulmonary disease were excluded. Patients with a known allergy to meperidine, buspirone or using monoamine oxidase inhibitors, as well as women of childbearing potential were not eligible for inclusion.

\section{Cooling procedure}

Cooling was initiated by the application of external cooling pads (EMCOOLS Flex.Pad, EMCOOLS-Emergency Medical Cooling Systems AG, Pfaffstätten, Austria) performed out of hospital by physicians on scene. The cooling pads were stored in a cooling box at approximately $-4^{\circ} \mathrm{C}$ before use. The cooling pads were applied on patient's back, thorax, abdomen and thighs and were removed after arrival at the catheterisation laboratory. At hospital arrival, patients received a bolus of $1000-2000 \mathrm{~mL}$ of ice-cold saline solution $\left(4^{\circ} \mathrm{C}\right)$. In the catheterisation laboratory, an endovascular cooling catheter (Accutrol 14Fr, Philips InnerCool RTx endovascular thermal control system; Philips Healthcare, California, USA) was placed into the inferior vena cava via a femoral vein, with the tip at the level of the diaphragm. The catheter position was checked by x-ray and adjusted as necessary. Target temperature was set to $34.0^{\circ} \mathrm{C}$. All three cooling methods have already been used in awake subjects for induction and maintenance of mild hypothermia. ${ }^{18} 19$ Immediately after inserting the cooling catheter, the arterial sheath was placed and primary percutaneous coronary intervention was performed according to the interventionist's best judgement.

Three hours after successful revascularisation (in case of unsuccessful revascularisation $3 \mathrm{~h}$ after reaching a core temperature $<35^{\circ} \mathrm{C}$ ), cooling was stopped, subjects were covered with a blanket and were allowed to rewarm passively.

\section{Temperature monitoring}

Out-of-hospital temperature measurements were performed by an infrared tympanic thermometer (Ototemp LighTouch, Exergen, Watertown, Massachusetts, USA). Once the invasive cooling catheter was in place, blood temperature was measured with the integrated thermistor within the distal tip of the Accutrol catheter and feedback to the RTx console. Prior to reperfusion temperature was updated to measure blood temperature at the time of wire-crossed lesion. After removal of the catheter temperature was measured with an infrared tympanic thermometer.

\section{Medication}

After baseline measurements (blood pressure, peripheral oxygen saturation, heart rate and tympanic temperature), an intravenous bolus of meperidine (Alodan; Gerot Pharma, Vienna, Austria) $1 \mathrm{mg} / \mathrm{kg}$ and $30 \mathrm{mg}$ oral buspirone (Buspar; Bristol-Myers Squibb, Vienna, Austria) were administered to prevent shivering. Meperidine infusion at a rate of $30 \mathrm{mg} / \mathrm{h}$ was started upon reaching the catheterisation laboratory. In case of shivering or discomfort an additional bolus of $20 \mathrm{mg}$ meperidine was given, followed by an increase of meperidine infusion by $5 \mathrm{mg} / \mathrm{h}$.

\section{Follow-up}

All adverse events (serious and non-serious) were collected from the time of enrolment until a clinical follow-up on day $45 \pm 15$ on an intention-to-treat basis. Adverse events were included, but were not limited to death, reinfarction, aortocoronary bypass surgery, acute heart failure, ventricular tachycardia/fibrillation, stroke, bradycardia, major or minor bleeding (according to thrombolysis in myocardial infarction bleeding score).

\section{Statistics}

Continuous variables are shown as mean $\pm \mathrm{SD}$, or as median and IQR, if not normally distributed. Nominal data are given as counts and percentages of total number. In this feasibility trial, no formal hypothesis testing or group comparisons were performed. To compare changes in vital signs and laboratory values from baseline, the paired t-test or Wilcoxon signed-rank test was used. A two-sided $\mathrm{p}$ value $<0.05$ was considered significant. SPSS software (V.20.0 for Mac, IBM Inc., Illinois, USA) and Microsoft Excel (V.12.0 for Mac, Microsoft Corp., Washington, USA) were used for statistical analysis.

\section{RESULTS}

A total of 19 patients (one woman) with a median age of 51 years (45-59) and a body mass index of 29.4 (25.7-31.6) were included in this pilot study. Baseline characteristics are shown in table 1.

Table 1 Baseline characteristics

\begin{tabular}{|c|c|}
\hline & $\mathrm{n}=19$ \\
\hline \multicolumn{2}{|l|}{ Age } \\
\hline Median years (IQR) & $51(45-59)$ \\
\hline \multicolumn{2}{|l|}{ Female gender } \\
\hline No./total no. (\%) & $1 / 19(5 \%)$ \\
\hline \multicolumn{2}{|l|}{ BMI } \\
\hline $\mathrm{kg} / \mathrm{m}^{2}(\mathrm{IQR})$ & $29.4(25.7-31.6)$ \\
\hline \multicolumn{2}{|c|}{ Known pre-existing coronary artery disease } \\
\hline No./total no. (\%) & $1 / 19(5 \%)$ \\
\hline \multicolumn{2}{|c|}{ Known pre-existing arterial hypertension } \\
\hline No./total no. (\%) & $10 / 19(53 \%)$ \\
\hline \multicolumn{2}{|c|}{ Known pre-existing diabetes } \\
\hline No./total no. (\%) & $1 / 19(5 \%)$ \\
\hline \multicolumn{2}{|c|}{ Known pre-existing hyperlipidaemia } \\
\hline No./total no. (\%) & $3 / 19(16 \%)$ \\
\hline \multicolumn{2}{|c|}{ Family history of coronary artery disease } \\
\hline No./total no. (\%) & $5 / 19(26 \%)$ \\
\hline \multicolumn{2}{|l|}{ Current smoker } \\
\hline No./total no. (\%) & $6 / 19(32 \%)$ \\
\hline \multicolumn{2}{|l|}{ Obesity (BMl>30 kg/m²) } \\
\hline No./total no. (\%) & $9 / 19(47 \%)$ \\
\hline \multicolumn{2}{|c|}{ Known pre-existing peripheral artery disease } \\
\hline No./total no. (\%) & $0 / 19(0 \%)$ \\
\hline
\end{tabular}


We excluded five patients from the analysis of the primary outcome. In three patients, we found no significant coronary stenosis. Two of these patients were classified as coronary vasospasm and one as a case of perimyocarditis. In these three cases, a temperature of $<35.0^{\circ} \mathrm{C}$ could be achieved at the time of abortion of angiography. In one case, cooling was aborted immediately after inclusion because the catheterisation laboratory was not available. One patient developed signs of cardiogenic shock early after inclusion and cooling initiation with cooling pads. Therefore, study procedures were aborted. This patient suffered from occlusion of the left main coronary artery and died from intractable cardiogenic shock.

In the remaining 14 cases that were eligible for primary outcome analysis, a median time of $45 \mathrm{~min}$ (31-85) from symptom onset to first medical contact (FMC) was recorded. Cooling was initiated at a median of 14 min (7-25) after FMC at a median tympanic temperature of $36.4^{\circ} \mathrm{C}(36.2-36.5)$ with the application of eight cooling pads (6-9). Patients arrived 40 min (29-46) after FMC at the emergency department and 48 min (40-56) after FMC in the catheterisation laboratory. At the time of arrival in the catheterisation laboratory, they had received $1000 \mathrm{~mL}(1000-1600)$ of $4^{\circ} \mathrm{C}$ cold saline. The first measured blood temperature was $35.9^{\circ} \mathrm{C} \quad(35.2-36.3)$. Door-to-balloon time was $59 \mathrm{~min}$ (44-74). Revascularisation was established 100 min (90-111) after FMC at an intervention time (time from arterial access to wire-crossed lesion) of $21 \mathrm{~min}$ $(16-27)$, at a blood temperature of $34.4^{\circ} \mathrm{C}\left(34.1-35.0^{\circ} \mathrm{C}\right.$, figure 1). In 11 patients (78\%), a core temperature below $35.0^{\circ}$ $\mathrm{C}$ at reperfusion of the culprit lesion could be reached. In three patients, the target temperature of $<35.0^{\circ} \mathrm{C}$ could not be achieved. In one case, the endovascular cooling device had an unidentified malfunction. In the other two cases, time from FMC to reperfusion was only 65 and $78 \mathrm{~min}$, respectively, whereas in the second case only $200 \mathrm{~mL}$ of cold fluid has been administered due to kinking of the vascular access line.
All 14 patients were cooled for $3 \mathrm{~h}$ at a target temperature between $34.0^{\circ} \mathrm{C}$ and $35.0^{\circ} \mathrm{C}$. After $3 \mathrm{~h}$, active cooling was stopped and patients were allowed to rewarm passively. We found no significant change in systolic blood pressure, heart rate or oxygen saturation during the cooling procedure. Whereas significant shivering (ie, peripheral shivering) was observed only in one patient, minor shivering episodes (ie, isolated facial or masticatory fasciculation) were present in all patients. All shivering conditions could be well controlled by adaption of the meperidine drip. In five cases (26\%), the meperidine drip had to be adjusted several times because of unpleasant sensation of cold, which resulted in an immediate relief of symptoms. All shivering and/or discomfort episodes occurred during endovascular cooling in the cath lab and resulted in the administration of 3 $(2-5)$ boli of meperidine $(20 \mathrm{mg})$ followed by an increase of the meperidine drip $(5 \mathrm{mg} / \mathrm{h})$. Clinical outcomes and adverse events of all 19 included patients are summarised in table 2 .

\section{DISCUSSION}

The present pilot trial demonstrates that a combined cooling strategy initiated in the out-of-hospital setting is feasible in patients with ongoing ST-elevation acute coronary syndrome (STE-ACS). In those patients who were eligible for analysis of the primary endpoint, we were able to reduce median temperatures from $36.4^{\circ} \mathrm{C}$ to $34.4^{\circ} \mathrm{C}$ at the time of reperfusion.

\section{Cooling}

Current treatment guidelines for patients with ongoing STE-ACS recommend that the time interval between FMC and reperfusion of the ischaemic myocardium to be as short as possible to minimise infarct size and thereby reducing short-term and long-term morbidity and mortality. ${ }^{1}$ Because of reperfusion injury that is known to include multimodal pathophysiologic consequences leading to cell death and subsequently to an

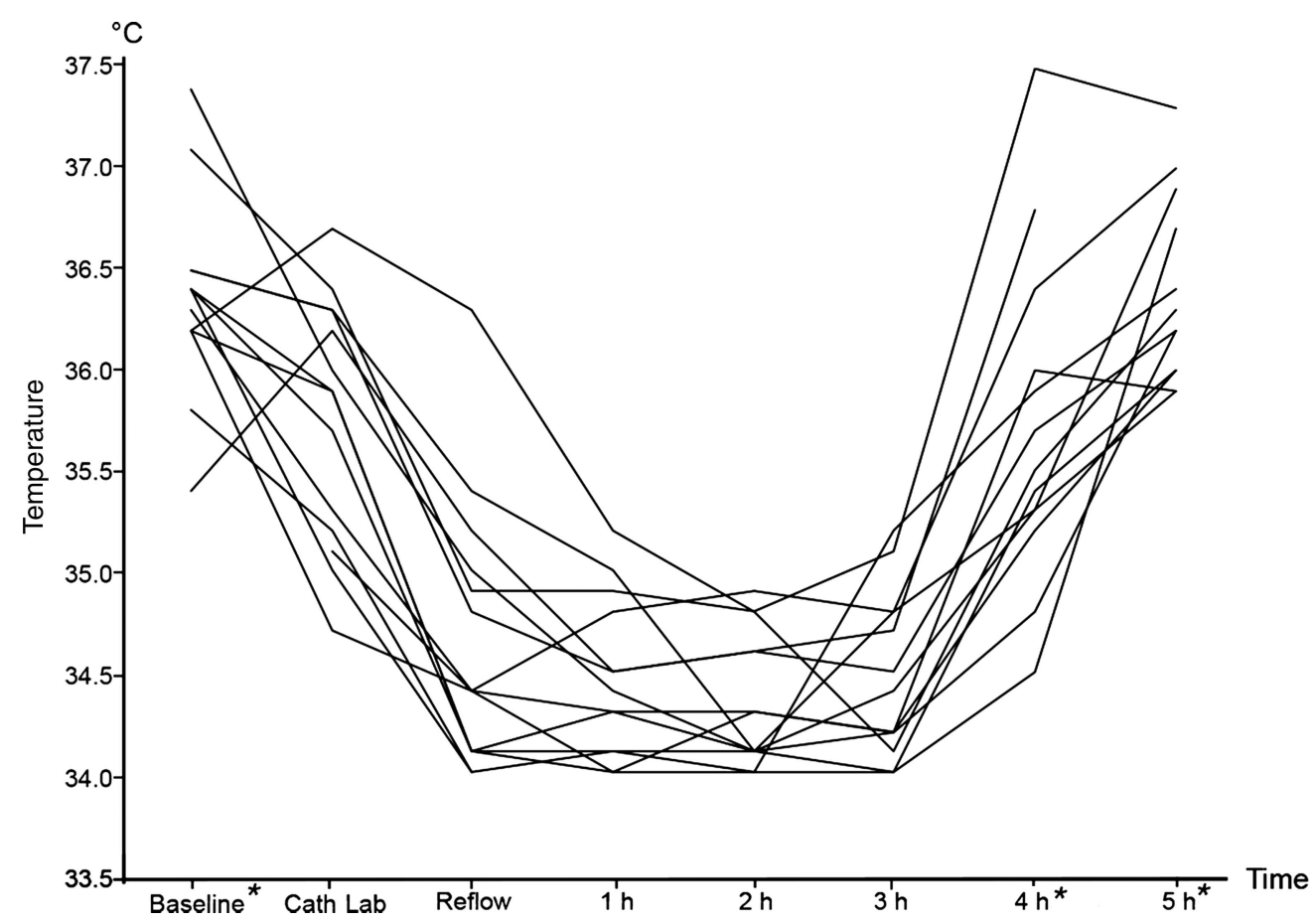

Figure 1 Individual temperature courses of 14 patients during preventive cooling in ST-elevation acute coronary syndrome. * Temperatures at these time points were measured with infrared tympanic thermometer. All other temperatures reflect blood temperature measured by the endovascular catheter. 
Table 2 Outcomes and adverse events

\begin{tabular}{|c|c|}
\hline & $\mathrm{N}=19$ \\
\hline \multicolumn{2}{|l|}{ Suspected infarct localisation, no./total no. (\%) } \\
\hline Anterior wall infarction & $9 / 19(47 \%)$ \\
\hline Posterior wall infarction & $10 / 19(53 \%)$ \\
\hline \multicolumn{2}{|l|}{ Pre-PCI TIMI grade flow*, no./total no. (\%) } \\
\hline 0 & $13 / 19(68 \%)$ \\
\hline 1 & $3 / 19(16 \%)$ \\
\hline 2 & 0 \\
\hline 3 & $3 / 19(16 \%)$ \\
\hline \multicolumn{2}{|l|}{ Culprit lesion, no./total no. (\%) } \\
\hline No significant coronary stenosis & $3 / 19(16 \%)$ \\
\hline Left main artery & $1 / 19(5 \%)$ \\
\hline Left anterior descending artery & $9 / 19(47 \%)$ \\
\hline Circumflex artery & $2 / 19(11 \%)$ \\
\hline Right coronary artery & $4 / 19(21 \%)$ \\
\hline \multicolumn{2}{|l|}{ Post-PCI TIMI grade flow*, no./total no. (\%) } \\
\hline 0 & $1 / 19(5 \%)$ \\
\hline 1 & 0 \\
\hline 2 & $1 / 19(5 \%)$ \\
\hline 3 & $17 / 19(90 \%)$ \\
\hline Peak level of creatine kinase, units/L (IQR) $\dagger$ & 3807 (1429-5585) \\
\hline Peak level of troponin $\mathrm{T}, \mathrm{ng} / \mathrm{mL}(\mathrm{IQR}) \dagger$ & $4.56(2.50-10.00)$ \\
\hline \multicolumn{2}{|l|}{ Killip classification, no./total no. (\%) } \\
\hline 1 & $13 / 19(68 \%)$ \\
\hline ॥ & $3 / 19(16 \%)$ \\
\hline III & $2 / 19(11 \%)$ \\
\hline IV & $1 / 19(5 \%)$ \\
\hline Recurrent ischaemia, no./total no. (\%) & 0 \\
\hline \multicolumn{2}{|l|}{ Major cardiac arrhythmias, no./total no. (\%) } \\
\hline Ventricular tachycardia & $2 / 19(11 \%)$ \\
\hline Ventricular fibrillation & 0 \\
\hline Asystole & 0 \\
\hline AV-Block $\geq 2^{\circ}$ & 0 \\
\hline Stroke & 0 \\
\hline Major/minor bleeding§ & 0 \\
\hline Cardiac arrest & $1 / 19(5 \%)$ \\
\hline Death & $1 / 19(5 \%)$ \\
\hline \multicolumn{2}{|l|}{ NYHA class at day $30 \S$} \\
\hline I & $10 / 18(56 \%)$ \\
\hline$\|$ & $6 / 18(33 \%)$ \\
\hline III & $2 / 18(11 \%)$ \\
\hline IV & 0 \\
\hline Infection within 30 days, no./total no. (\%) & $3 / 19(16 \%)$ \\
\hline
\end{tabular}

increase in infarct size ${ }^{20}$ new treatment strategies to limit reperfusion injury are needed.

Existing human data indicate that a reduction of the core temperature to less than $35.0^{\circ} \mathrm{C}$ at the time of reperfusion will reduce infarct size, whereas induction of hypothermia after reperfusion has no effect on infarct size. ${ }^{16-18}$ As time is crucial in STE-ACS, the induction of hypothermia is claimed not to extend the time to reperfusion. As a logic consequence, cooling should start at the time of FMC in the out-of-hospital setting without delaying current time limits. In this study, we could show that early induction of hypothermia provided by emergency medical teams on scene is able to lower patients' temperatures by $0.5^{\circ} \mathrm{C}$ until arrival in the catheterisation laboratory. This should be interpreted under consideration of two different types of temperature measurements (tympanic temperature out-of-hospital; blood temperature in-hospital). In cardiac arrest patients treated with therapeutic hypothermia, tympanic temperatures tended to be $0.6^{\circ} \mathrm{C}$ lower than those measured in the femoral vein. ${ }^{21}$ Considering relatively low distances to the next catheterisation laboratory in an urban setting, out-of-hospital cooling might become more relevant in rural areas. The delay caused by study-related interventions seems to be low when comparing with pre-existing data on routine timing at our hospital. ${ }^{22}$ This is consistent with the findings of Götberg et $a l^{18}$ who found no significant influence of the cooling procedure on the door-to-balloon time.

\section{Safety}

In a previous study, no signs of pulmonary congestion/oedema were reported after the administration of comparable amounts of cold saline in patients with STE-ACS. ${ }^{18}$ In patients with cardiac arrest, a comparable bolus volume was administered without clinically relevant pulmonary congestion. ${ }^{23}$ In addition, the rate of arrhythmic events is similar to existing data. ${ }^{24} 25$ There were no adverse events associated with the cooling procedure itself. Shivering could be avoided by a therapeutic regimen used in previous cooling studies without side effects. ${ }^{19}$ Many other antishivering strategies are described in the literature. $^{26-28}$ None of the existing regimen fulfils the key points without interacting with respiration or haemodynamics, so continuous monitoring and adaption of dosage are mandatory to prevent adverse events. Future studies should focus on the development of an easy to use and safe possibility to suppress shivering. As there were no significant changes in blood pressure, oxygen saturation or heart rate during the cooling procedure, we have no evidence for causing an increased afterload and therefore a compromised cardiac function by surface cooling or endovascular cooling.

\section{Limitations}

The fact that we were not able to reduce temperatures to predefined levels in all patients highlights the limitation of this approach caused by the demand of immediate reperfusion. As we are not able to measure blood temperature in the out-of-hospital setting and tympanic temperature underlies many variations, we are not able to provide reliable data on the effect of out-of-hospital cooling. As there was no control group in this trial, the data on safety, adverse events as well as procedure-related time loss are limited.

\section{CONCLUSION}

The temperature care bundle used in this trial is feasible and safe for induction of prereperfusion hypothermia in patients with ongoing STE-ACS. Further studies are needed to evaluate if changes in the cooling procedure enable to get more patients within therapeutic ranges of hypothermia and if this approach improves outcomes in patients with ongoing STE-ACS.

Acknowledgements In memory of Reinhard Malzer, who died unexpectedly on 13 April 2013. Thank you for your infinite humanity and great support. We are indebted to all emergency physicians, paramedics and nurses for their enthusiastic cooperation and to the patients who participated in this study for their trust and support.

Contributors All authors have made substantial contributions to all of the following: (1) the conception and design of the study, or acquisition of data, or 
analysis and interpretation of data, (2) drafting the article or revising it critically for important intellectual content and (3) final approval of the version to be submitted.

\section{Competing interests None.}

Ethics approval Ethical review board of the Medical University of Vienna (Protocol number: 492/2011; clinicaltrials.gov registration number: NCT01864343).

Provenance and peer review Not commissioned; externally peer reviewed.

Open Access This is an Open Access article distributed in accordance with the Creative Commons Attribution Non Commercial (CC BY-NC 3.0) license, which permits others to distribute, remix, adapt, build upon this work non-commercially, and license their derivative works on different terms, provided the original work is properly cited and the use is non-commercial. See: http://creativecommons.org/ licenses/by-nc/3.0/

\section{REFERENCES}

1 Task Force on the management of ST-segment elevation acute myocardial infarction of the European Society of Cardiology (ESC)Steg PG, James SK, et al. ESC Guidelines for the management of acute myocardial infarction in patients presenting with ST-segment elevation. Eur. Heart J. 2012;33:2569-619.

2 Yellon DM, Hausenloy DJ. Myocardial reperfusion injury. N Engl J Med 2007;357:1121-35.

3 Miller TD, Christian TF, Hopfenspirger MR, et al. Infarct size after acute myocardial infarction measured by quantitative tomographic $99 \mathrm{mTc}$ sestamibi imaging predicts subsequent mortality. Circulation 1995;92:334-41.

4 Burns RJ, Gibbons RJ, Yi Q, et al. The relationships of left ventricular ejection fraction, end-systolic volume index and infarct size to six-month mortality after hospital discharge following myocardial infarction treated by thrombolysis. J Am Coll Cardiol 2002;39:30-6.

5 Hypothermia after Cardiac Arrest Study Group. Mild therapeutic hypothermia to improve the neurologic outcome after cardiac arrest. N Engl J Med 2002;346:549-56.

6 Bernard SA, Gray TW, Buist MD, et al. Treatment of comatose survivors of out-of-hospital cardiac arrest with induced hypothermia. $N$ Engl J Med 2002;346:557-63.

7 Hale SL, Dae MW, Kloner RA. Hypothermia during reperfusion limits "no-reflow" injury in a rabbit model of acute myocardial infarction. Cardiovasc Res 2003;59:715-22.

8 Dae MW, Gao DW, Sessler DI, et al. Effect of endovascular cooling on myocardial temperature, infarct size, and cardiac output in human-sized pigs. Am J Physiol Heart Circ Physiol 2002;282:H1584-91.

9 Ly HQ, Denault A, Dupuis J, et al. A pilot study: the Noninvasive Surface Cooling Thermoregulatory System for Mild Hypothermia Induction in Acute Myocardial Infarction (the NICAMI Study). Am Heart J 2005;150:933.

10 Götberg M, Olivecrona GK, Engblom H, et al. Rapid short-duration hypothermia with cold saline and endovascular cooling before reperfusion reduces microvascular obstruction and myocardial infarct size. BMC Cardiovasc Disord 2008;8:7.
11 Otake H, Shite J, Paredes OL, et al. Catheter-based transcoronary myocardial hypothermia attenuates arrhythmia and myocardial necrosis in pigs with acute myocardial infarction. J Am Coll Cardiol 2007;49:250-60.

12 Götberg M, van der Pals J, Olivecrona GK, et al. Mild hypothermia reduces acute mortality and improves hemodynamic outcome in a cardiogenic shock pig model. Resuscitation 2010;81:1190-6

13 Hale SL, Kloner RA. Myocardial temperature in acute myocardial infarction: protection with mild regional hypothermia. Am J Physiol 1997;273:H220-7.

14 Simkhovich BZ, Hale SL, Kloner RA. Metabolic mechanism by which mild regional hypothermia preserves ischemic tissue. J Cardiovasc Pharmacol Ther 2004;9:83-90.

15 Tissier R, Chenoune M, Ghaleh B, et al. The small chill: mild hypothermia for cardioprotection? Cardiovasc Res 2010;88:406-14.

16 COOL-MI Presentation [Internet]. tctmd.com. [cited 2013 Apr 10]; http://www. tctmd.com/show.aspx?id=398\&ref_id $=59364$

17 ICE-IT Presentation TCT2004 [Internet]. scribd.com. [cited 2013 Apr 10]; http:/l www.scribd.com/cooldoc25/d/40117148-ICE-IT-Presentation-TCT2004

18 Götberg M, Olivecrona GK, Koul S, et al. A pilot study of rapid cooling by cold saline and endovascular cooling before reperfusion in patients with ST-elevation myocardial infarction. Circ Cardiovasc Interv 2010;3:400-7.

19 Testori C, Sterz F, Behringer W, et al. Surface cooling for induction of mild hypothermia in conscious healthy volunteers - a feasibility trial. Crit Care 2011;15: R248.

20 Fröhlich GM, Meier P, White SK, et al. Myocardial reperfusion injury: looking beyond primary PCl. Eur Heart J 2013;34:1714-22.

21 Krizanac D, Stratil P, Hoerburger D, et al. Femoro-iliacal artery versus pulmonary artery core temperature measurement during therapeutic hypothermia: an observational study. Resuscitation 2012;84:805-9.

22 Havel C, Schreiber W, Christ G, et al. Accelerated management of patients with ST-segment elevation myocardial infarction in the ED. Am J Emerg Med 2011;29:650-5.

23 Kliegel A, Janata A, Wandaller C, et al. Cold infusions alone are effective for induction of therapeutic hypothermia but do not keep patients cool after cardiac arrest. Resuscitation 2007;73:46-53.

24 Shotan A, Blondheim DS, Gottlieb S, et al. Comparison of outcome of recurrent versus first ST-segment elevation myocardial infarction (from national Israel surveys 1998 to 2006). Am J Cardiol 2011;107:1730-7.

25 Cubeddu RJ, Palacios IF, Blankenship JC, et al. Outcome of patients with ST-segment elevation myocardial infarction undergoing primary percutaneous coronary intervention during on- versus off-hours (A Harmonizing Outcomes With RevasculariZatiON and Stents in Acute Myocardial Infarction [HORIZONS-AMI] Trial Substudy). Am J Cardiol 2013;111:946-54.

26 Doufas AG, Lin C-M, Suleman M-I, et al. Dexmedetomidine and meperidine additively reduce the shivering threshold in humans. Stroke 2003;34:1218-23.

27 Lenhardt R, Orhan-Sungur M, Komatsu R, et al. Suppression of shivering during hypothermia using a novel drug combination in healthy volunteers. Anesthesiology 2009;111:110-15.

28 Hostler D, Northington WE, Callaway CW. High-dose diazepam facilitates core cooling during cold saline infusion in healthy volunteers. Appl Physiol Nutr Metab 2009;34:582-6. 